\title{
Pengaruh Regulasi dan Kolaborasi Terhadap Literasi Keuangan dalam Upaya Penerapan Financial Technology pada Usaha Kecil dan Menengah
}

\author{
Christian Herdinata \& Cliff Kohardinata \\ International Business Management \\ Fakultas Manajemen dan Bisnis Universitas Ciputra \\ e-mail: christian.herdinata@ciputra.ac.id \& ckohardinata@ciputra.ac.id
}

\begin{abstract}
Financial technology (fintech) has provided access to many parties who do not have a bank account to enter the formal business sector. The application of fintech is proven to be able to open greater access to formal financial services, encourage economic growth, and inclusive and sustainable development. To support the application of fintech in Indonesia, the purpose of this study is to determine the effect of regulation and collaboration on financial literacy in small and medium businesses in East Java - Indonesia. There are 2 (two) hypotheses from this study, namely regulation has a significant effect on financial literacy and collaboration has a significant effect on financial literacy. This research was conducted through a quantitative approach with a research sample of 148 MSMEs in Surabaya and using technology applications in conducting trade transactions. The analysis technique used is multiple linear regression. The results of this study are that regulation and collaboration have a significant effect on financial literacy. Therefore, this research can help many parties, namely the government, entrepreneurs, and consumers in providing a complete and comprehensive understanding related to financial literacy in small and medium enterprises related to the application of financial technology.
\end{abstract}

Keywords: financial technology (fintech), financial literacy, regulation, collaboration

\section{PENDAHULUAN}

Kementerian PPN/Bappenas memandang fintech sebagai salah satu elemen strategis untuk mewujudkan keuangan inklusif, sekaligus dapat menciptakan pembangunan berkeadilan bagi masyarakat miskin. Pada 2016, Asosiasi Fintech Indonesia mendata setidaknya terdapat 140 pemain fintech di Indonesia. Diharapkan dengan semakin meningkatnya literasi keuangan masyarakat Indonesia, maka investasi jangka panjang dan penempatan modal pada berbagai sektor produktif ditingkatkan. Tiga prioritas pembangunan yang dapat digerakkan oleh pemanfaatan fintech. Pertama, mobilisasi modal meningkatkan aktivitas ekonomi kelompok yang kurang terlayani, seperti masyarakat berpenghasilan rendah (MBR) dan usaha kecil menengah (UKM). Ke$d u a$, mobilisasi uang untuk membiayai infra- struktur dasar, seperti sanitasi dan listrik. Ketiga, mobilisasi dana untuk mendorong pembangunan infrastruktur yang berkelanjutan, seperti energi bersih, dan atau membiayai inovasi yang penting dalam rangka peningkatan produksi pertanian dan perikanan. Nofita Wulansari (2017) mengungkapkan bahwa peran UMKM di Indonesia menjadi hal yang penting dalam mendorong pertumbuhan ekonomi. UMKM mampu bertahan dan menyelamatkan perekonomian bangsa ketika terjadi krisis. Pada saat ini UMKM telah menyesuaikan dengan revolusi industri 4.0 yang terjadi. Hal yang paling dominan terlihat yaitu melalui financial technology (fintech) yang digunakan oleh UMKM. Iman (2016) merangkum definisi fintech sebagai implementasi dan pemanfaatan teknologi untuk peningkatan layanan jasa perbankan dan keuangan. Oleh karena itu, fintech 
dapat menjadi solusi seperti diungkapkan oleh Anner (2015) bahwa fintech secara garis besar adalah teknologi yang digunakan untuk mengirimkan solusi finansial. Hal lain yang menarik yaitu fintech dapat menyebabkan munculnya inovasi disruptif jika tidak diantisipasi dengan baik oleh dunia usaha yang dapat menyebabkan kejatuhan. (Hadad, 2017). Maka dari itu, menjadi penting untuk menguji pengaruh kolaborasi dan literasi keuangan terhadap penerapan $f_{i-}$ nancial technology.

\section{KAJIAN PUSTAKA}

\section{Regulasi}

Saat ini banyak negara memiliki lembaga khusus untuk mengendalikan perusahaan di pasar keuangan. Misalnya, di Inggris ada Financial Conduct Authority (FCA), sebuah badan nonpemerintah independen. FCA memiliki kewajiban dan tanggung jawab untuk mengatur perusahaan di sektor keuangan dan menerapkan standar serta persyaratan untuk produk keuangan, termasuk di dalamnya mengatur pemasaran dan keuangan perilaku produk sampai membuat larangan apabila terlihat penerapannya kurang tepat (Kalmykova dan Tyabova, 2016). Kejelasan regulasi dapat berfungsi sebagai dasar untuk sistem pembiayaan non-utang berbasis aset (Graff, 2013). Struktur keuangan yang dimaksud untuk menghindari kontraktual jangka panjang pengaturan antara pembeli properti dan pemodal properti selain jangka panjang sewa hak kepemilikan pemilikan uang oleh pembeli properti (Graff, 2013). Kelas baru struktur keuangan memiliki lebih sedikit, dan lebih sederhana, jangka panjang ketentuan yang mirip kontrak daripada contoh-contoh standar dari keuangan yang sesuai syariah dan pembiayaan utang konvensional (Graff, 2013). Banyak penelitian berpendapat bahwa pemerintah sebaiknya menjawab tantangan regulasi yang signifikan (Philippon, 2016).

\section{Kolaborasi}

Kolaborasi dengan perusahaan lain dalam suatu ekosistem bisnis akan menghasilkan kompetensi untuk mencapai massa kritis minimum adopter dan probabilitas yang lebih tinggi sehingga produk inovatif terkait keuangan akan mampu berhasil diterapkan (Teja, 2017). Ekosistem bisnis dan pemerintah perlu mempertahankan kolaborasi peran aktif ini untuk mendorong pembangunan kolaborasi fintech di dalam dan di seluruh ekosistem bisnis. Oleh karena itu, transformasi pengguna menjadi pengembang-pengguna dapat membuka peluang baru (Overholm, 2014; McKelvey et al, 2015). Selanjutnya, mengikat sebuah jaringan pengguna dan mengubah peran pengguna menjadi pengembang maka asumsinya perusahaan akan mendapatkan lebih banyak penerimaan ( $\mathrm{Lu}$ et al, 2014). Oleh karena itu, Maharesi (2017) mengungkapkan bahwa melalui berkolaborasi maka ekspansi pemanfaatan fintech bagi masyarakat luas dapat bernilai dan berdampak signifikan dalam menggerakkan perekonomian hingga ke lapisan bawah.

\section{Literasi Keuangan}

Secara umum, arti literasi keuangan yaitu sebuah kecakapan atau kesanggupan dalam hal keuangan yang dimiliki oleh seseorang. Ketika seseorang memiliki literasi keuangan yang baik (well literate), maka dia akan mampu melihat uang dengan sudut pandang yang berbeda serta mampu mengendalikan kondisi keuangannya. Potensial fintech pada industri keuangan untuk menciptakan stabilitas dan akses ke layanan (Philippon, 2016). Oleh karena itu, proses substitusi teknologi di dalamnya jauh lebih baik untuk mendo- 
rong investasi jangka panjang dan penempatan modal pada berbagai sektor-sektor produktif (Rong et al., 2013). Tantangan terbesar pengembangan inovasi keuangan ini merupakan produk unggulan yang fungsinya diterima dalam kebiasaan penggunaan sistem pembayaran harian pengguna tanpa mengubah kebiasaan pengguna (Teja, 2017).

Oleh karena itu, dalam penelitian ini dibentuk hipotesis penelitian berkaitan dengan regulasi dan kolaborasi serta literasi keuangan, sebagai berikut.

$\mathrm{H}_{1}$ : Regulasi berpengaruh signifikan terhadap literasi keuangan dalam penerapan financial technology.

$\mathrm{H}_{2}$ : Kolaborasi berpengaruh signifikan terhadap literasi keuangan dalam penerapan financial technology.

\section{METODOLOGI PENELITIAN}

Subjek penelitian fokus pada UMKM yang ada di Jawa Timur yang dipilih menggunakan teknik non-probability sampling. Peneliti memilih sampel dengan convenience sampling sebanyak 148 UMKM yang menjadi subjek penelitian. Sumber data yang digunakan dalam penelitian ini berasal dari data primer melalui kuesioner dan data sekunder. Adapun pengukuran data dilakukan dalam penelitian ini menggunakan skala likert. Pengukuran validitas adalah kecermatan atau ketepatan tes tersebut dalam menjalankan fungsi ukurnya Suryabrata (2000) dalam Rahayuni (2015). Pernyataan dikatakan valid apabila nilai signifikansi dari korelasinya $\leq 0,05$ atau 5\% (Lingga, 2012). Pengukuran reliabilitas untuk melihat pertanyaan kuesioner mampu secara konsisten merefleksikan konstruk yang sedang diukur. Sebuah item tertentu dalam kuesioner harus dengan konsisten menghasilkan hal yang relatif sama dengan keseluruhan kasus yang dilihat melalui pengukuran dengan teknik Cronbach's Alpha dengan reliabilitas dapat diterima jika Cronbach's Alpha $\geq 0,6$ (Priyatno, 2014:64). Teknik analisis yang digunakan dalam penelitian ini yaitu regresi linier berganda.

\section{HASIL PENELITIAN}

Hasil dari model penelitian ini menunjukkan bahwa uji $\mathrm{F}$ signifikan sehingga memenuhi good of fit sebuah model. Sampel penelitian terdiri dari 148 usaha kecil menengah di Jawa Timur - Indonesia dalam penelitian dan hasil Uji F dapat dilihat pada Tabel 1.1.

Tabel 1.1 Hasil Uji F

\begin{tabular}{|ll|r|r|r|c|c|}
\hline \multicolumn{1}{|c|}{ Model } & $\begin{array}{c}\text { Sum of } \\
\text { Squares }\end{array}$ & \multicolumn{1}{c|}{ df } & $\begin{array}{c}\text { Mean } \\
\text { Square }\end{array}$ & F & Sig. \\
\hline 1 Regression & 22.751 & 2 & 11.376 & 43.216 & $.000^{\mathrm{b}}$ \\
& Residual & 38.168 & 145 & .263 & & \\
Total & 60.919 & 147 & & & \\
\hline
\end{tabular}

a. Dependent Variable: Y_Lit

b. Predictors: (Constant), X2_Kol, X1_Reg

Berikut merupakan hasil Uji $\mathrm{t}$ terhadap pengujian pengaruh regulasi terhadap penerapan ilustrasi keuangan ditemukan berpengaruh signifikan dengan nilai 0.001 lebih kecil dari 0.05. Oleh karena itu, hipotesis $\left(\mathrm{H}_{1}\right)$ diterima. Selanjutnya, untuk pengujian pengaruh kolaborasi terhadap penerapan financial technology berpengaruh signifikan dengan nilai 0.000 lebih kecil dari 0.05. Oleh karena itu hipotesis $\left(\mathrm{H}_{2}\right)$ diterima. Hasil Uji t dapat dilihat pada Tabel 1.2.

Tabel 1.2 Hasil Uji t

\begin{tabular}{|c|c|c|c|c|c|c|}
\hline & \multirow{2}{*}{ Model } & \multicolumn{2}{|c|}{$\begin{array}{c}\text { Unstandardized } \\
\text { Coefficients }\end{array}$} & \multirow{2}{*}{\begin{tabular}{|c|}
$\begin{array}{c}\text { Standardized } \\
\text { Coefficients }\end{array}$ \\
Beta
\end{tabular}} & \multirow{2}{*}{$\mathrm{t}$} & \multirow{2}{*}{ Sig. } \\
\hline & & B & $\begin{array}{l}\text { Std. } \\
\text { Error }\end{array}$ & & & \\
\hline \multirow[t]{3}{*}{1} & (Constant) & 2.202 & .168 & & 13.119 & .000 \\
\hline & X1_Reg & .201 & .061 & .299 & 3.283 & $.001\left(^{*}\right)$ \\
\hline & $\mathrm{X} 2 \_\mathrm{Kol}$ & .255 & .064 & .364 & 3.994 & $.000\left(^{*}\right)$ \\
\hline
\end{tabular}

Keterangan:

Dependent Variable $=$ Y_PF

$\left.{ }^{*}\right)$ = Sig. 0.05 
Hasil penelitian menunjukkan bahwa pengaruh regulasi terhadap literasi keuangan berpengaruh signifikan. Hal ini menunjukkan bahwa regulasi memiliki pengaruh dalam peningkatan literasi keuangan. Hal ini diungkapkan oleh Graff (2013) yang menyatakan bahwa kejelasan regulasi dapat berfungsi sebagai dasar untuk sistem pembiayaan non-utang berbasis asset. Oleh karena hal ini perlu mendapat dukungan dari pemerintah dari segi regulasi. Banyak penelitian berpendapat bahwa pemerintah sebaiknya menjawab tantangan regulasi yang signifikan (Philippon, 2016).

Pengaruh kolaborasi terhadap literasi keuangan berpengaruh signifikan. Hal ini menunjukkan bahwa kolaborasi memiliki pengaruh yang penting dalam peningkatan literasi keuangan. Oleh karena itu, transformasi pengguna menjadi pengembang dapat membuka peluang baru (Overholm, 2014; McKelvey et al., 2015). Maka dari itu, ekosistem bisnis dan pemerintah perlu mempertahankan kolaborasi peran aktif ini untuk mendorong pembangunan kolaborasi fintech di dalam dan di seluruh ekosistem bisnis.

\section{KESIMPULAN}

Penelitian ini menemukan bahwa regulasi dan kolaborasi berpengaruh signifikan terhadap literasi keuangan. Hal ini menunjukkan bahwa regulasi dan kolaborasi merupakan hal yang penting dalam upaya peningkatan literasi keuangan dalam penerapan financial technology. Oleh karena itu, peran pemerintah dalam pembuatan regulasi dan pihak swasta dan masyarakat yang menjalankan peraturan harus memiliki sinergi sehingga menunjang dalam mengoptimalisasi regulasi. Selain itu, kolaborasi yang ada perlu dibangun antara pemerintah, pihak swasta, masyarakat umum dan konsumen untuk dapat saling bersinergi dalam meningkatkan literasi keuangan.

\section{DAFTAR RUJUKAN}

Arner, Douglas W; Barberist, Janos; \& Buckley, Ross P. 2016. The Evolution of Fintech: A New Post-Crisis Paradigm? Georgetown Journal of International Law, Vol. 47, Th. 2016.

Hyytinen, A., Pajarinen, M., \& Rouvinen, P. 2015. Does Innovativeness Reduce Startup Survival rates? Journal of Business Venturing, 30, 564-581.

Hadad, Muliaman D. 2017. Financial Technology (Fintech) di Indonesia, Kuliah Umum tentang FinTech - IBS, OJK Jakarta, 2 Juni 2017.

Iman, Nofie. 2016. Financial Technology dan Lembaga Keuangan, Gathering Mitra Linkage Bank Syariah Mandiri Hotel Grand Aston Yogyakarta, 22 November 2016.

Ion, Alexadra. 2016. Financial Technology (Fintech) and Its Implementation on the Romanian Non-Banking Capital Market. Practical Application of Science. Vol. IV, Issue 2.

Kalmykova, Ekaterina \& Anna Ryabova. 2016. FinTech Market Development Perspectives. SHS Web of Conferences, Vol. 10.

Lu, C., Rong, K., You, J., \& Shi, Y. 2014. Business Ecosystem and Stakeholders' Role Transformation: Evidence from Chinese Emerging Electric Vehicle Industry. Expert Systems with Applications, 41, 45794595.

Maharesi, Yogie. 2017. Fintech dan Transformasi Industri Keuangan, Departemen Komunikasi dan Internasional Otoritas Jasa Keuangan, industry.co.id, 2 August 2017. 
http://www.pwc.com/id/en/mediacentre/ pwc-innews/2017/indonesian/fintech-dan transformasi-industri-keuangan.html.

McKelvey, M., Zaring, O., \& Ljungberg, D. 2015. Creating Innovative Opportunities through Research Collaboration: An Evolutionary Framework and Empirical Illustration in Engineering. Technovation, 3940, 26-36.

Nofita Wulansari, Akselerasi Pertumbuhan Ekonomi Melalui Sinergi UMKM dan Good Governance di Indonesia, Prosiding Seminar Nasional dan Call For Paper Ekonomi dan Bisnis (SNAPER-EBIS 2017) - Jember, 27-28 Oktober 2017 (hal 262268) ISBN : 978-602-5617-01-0.

Overholm, H. 2014. Collectively Created Opportunities in Emerging Ecosystems: The Case of Solar Service Ventures. Technovation, 39-40, 14-25.
Rong, Ke. \& Yongjiang Shi. 2013. Business Ecosystem Extension: Facilitating the Technology Substitution. International Journal of Technology Management. Vol. 63, No. 3-4.

Stewart, Harrison \& Jan Jurjens. 2018. Data Security and Consumer trust in Fintech Innovation in Germany.

Teja, Adrian. 2017. Indonesian Fintech Business: New Innovations or Foster and Collaborate in Business Ecosystems? The Asian Journal of Technology Management, Vol. 10, No. 1, pp 10-18.

Philippon, Thomas. 2016. The Fintech Opportunity. National Bureu of Economic research. http://www.nber.org/papers/w 22476.

Priyatno, Duwi. 2014. SPSS 22 Pengolah Data Terpraktis. Yogyakarta: Andi. 